\title{
JCT building contracts: What's new?
}

Received (in revised form): 26th March, 2008

\begin{abstract}
Jessica Taylor
is a partner in the Projects and Construction department of city solicitors and Law Firm of the Year 2007 (The Lawyers Awards 2007), Trowers \& Hamlins. She has been involved in the construction industry for over 19 years and is a former deputy director of the Quantity Surveyors Division of the RICS. She specialises in non-contentious construction and engineering law advising institutional clients, banks, contractors, consultants and the public sector on a wide range of projects.
\end{abstract}

Correspondence: Jessica Taylor, Trowers \& Hamlins, Sceptre Court, 40 Tower Hill, London EC3N 4DX, UK; Tel: +44 (0)20 7423 8388; E-mail: jtaylor@trowers.com

\section{Abstract}

This paper is based on a lecture (of the same title) given by the author to attendees of the Royal Institution of Chartered Surveyors (RICS) Spring 2007 Building Surveyors Annual Briefing. It also contains a new section summarising some of the changes in the intervening months towards the end of this paper. In 2005 JCT and Sweet \& Maxwell started a new arrangement whereby Sweet \& Maxwell would publish all JCT's contracts from then onwards. The change in publisher also heralded a change in the contracts themselves - in terms of layout, drafting style and, on occasion, risk allocation between the employer and contractor. This paper will provide a brief overview of the changes, look at some of the alterations in more detail and consider some of the key changes since Spring 2007. Journal of Building Appraisal (2008) 3, 259-266. doi:10.1057/jba.2008.7

\section{Keywords:}

Joint Contracts Tribunal, JCT, new building contract forms

\section{INTRODUCTION}

The Joint Contracts Tribunal (JCT), which represents a cross-section of the construction industry including employers and construction clients, contractors, consultants and specialists, was established in 1931 and has for many decades produced (and still produces) standard forms of contracts, guidance notes and other standard documentation for use in the construction industry.

The current membership of the JCT includes the British Property Federation, the Construction Confederation, the Local Government Association, the National Specialist Contractors Council, the Royal Institution of Chartered Surveyors, the Association of Consulting Engineers, the Royal Institute of British Architects and the Scottish Building Contract Committee. Members are party to one of five colleges that represent the interests of employers, clients and local authorities; consultants; contractors, specialists and subcontractors and the Scottish building industry.

The JCT Council, its working parties, subcommittees and the colleges mentioned above consider and agree the contract documentation to be published. As from May 2005 Sweet \& Maxwell took over responsibility for publishing the JCT's contracts from the Royal Institute of British Architect's publishing house and is responsible for publishing all the contracts and associated documentation produced by the JCT. This switch to Sweet \& Maxwell also heralded an overhaul of the JCT suite of contracts which this paper will look at in more detail. 


\section{WHAT DOES JCT PUBLISH?}

JCT provides a range of building contracts, subcontracts, warranties (or duty of care deeds) and associated guidance notes. The building contracts include contracts for use on traditionally procured projects (either lump sum, measurement or cost plus), contracts where contractor's design is involved, term contracts and contracts where the contractor is undertaking more a management role (either construction management or management contracting). This paper will concentrate on the main JCT building contracts.

\section{CHANGES TO THE 'LOOK' OF JCT CONTRACTS}

Changes to the 'look' are the easiest to spot:

1. Each contract has a yellow cover with a coloured band in the middle of it to signify different families or specialisations - for example, the design and build contract has a deep pink band, the intermediate building contract has a brown band, the minor works contract has an orange band and the framework agreement has a turquoise band. This should make it easier to find contracts in the same 'family' and reinforces the brand image of JCT contracts which previously had different cover layouts and colours.

2. The internal layout has been revised by the use of sections to make the contracts clearer, easier to navigate and to promote brand consistency. Each contract now contains the following sections (rather than clauses) (with provisions of varying length and detail depending on the form being used):

- Section 1: Definitions and Interpretation

- Section 2: Carrying out the Works

- Section 3: Control of the Works

- Section 4: Payment

- Section 5: Measurement and Valuation

- Section 6: Injury, Damage and Insurance

- Section 7: Assignment, Third Party Rights and Collateral Warranties

- Section 8: Termination

- Section 9: Settlement of Disputes

Users of the 2005 suite therefore know that whatever contract is being used that payment will be set out in Section 4 instead of having to scour one of the 1998 editions where the payment provisions are found in different clauses. Headings, subheadings and typefaces have been standardised as well.

3. All project-specific information is set out in the Contract Particulars (even in the shorter forms like the Minor Works Building Contract and the Intermediate Building Contract) where before it was scattered through the text. In the Standard Forms of Contract and the Design \& Build Contract the Contract Particulars are essentially the same as Appendix 1 in the 1998 editions but at the front of the published form for ease of use.

4. There is a greater use of schedules to include detailed procedures and information for example insurance options and fluctuation provisions.

5. The drafting and terminology has been simplified again to make the contracts easier to use.

6. There are no separate supplements covering provisions for fluctuations, sectional completion and contractor's design portion in the 2005 suite - the provisions are now incorporated within the contract itself if appropriate. 
7. Amendments are not published separately as loose leafs (save for the six months after the change is made) - rather they are incorporated into the relevant contract and a revised version will be published immediately.

\section{SIMPLIFICATION}

Rather than having a separate local authority and 'private' versions of the With Quantities, Without Quantities and With Approximate Quantities of JCT contracts, these have been merged to form one version of each contract with optional clauses where that contract is being used by a local authority.

As well as deleting a number of contracts some of those which remain have been renamed (Table 1).

The changes, however, are not limited to contract titles. Much of the terminology and definitions within the contracts has also been updated/simplified (see Table 2 for examples). While these changes may seem insignificant they reduce the length of the contracts making them more manageable and easier to understand.

The new contracts also increase the use of default provisions in the Contract Particulars. For example, if a specific number of months is not inserted for the rectification period the default of six months will apply; if a retention percentage is not included the default of 3 per cent will apply; professional indemnity insurance will be required on an aggregate basis per insurance period if the Contract Particulars are not specifically amended to set out the basis on which it is required (ie for each and every claim or for each occurrence or series of occurrences arising out of any one event). While the use of default provisions has the benefit of avoiding uncertainty in the event that one of the options is not chosen, they may have unintended consequences for an unfamiliar user.

\section{JCT DOWNSIZED}

As well as improving layout and updating the language used, the content of the standard forms has been streamlined as well and a number of provisions have either been removed or revised either because they were not commonly used, did not reflect market practice or were not necessary.

Table I: Examples of renamed contracts

\begin{tabular}{ll}
\hline $\mathbf{1 9 9 8}$ edition & $\mathbf{2 0 0 5}$ editions \\
\hline Standard Form of Building Contract & Standard Building Contract \\
With Contractor's Design & Design \& Build Contract \\
Intermediate Form of Building Contract & Intermediate Building Contract \\
Agreement for Minor Building Works & Minor Works Building Contract \\
\hline
\end{tabular}

Table 2: Changes to terminology and definitions

\begin{tabular}{ll}
\hline Old terminology & New terminology \\
\hline Determination & Termination \\
Defects Liability Period & Rectification Period \\
Extension of Time & Adjustment of Completion Date \\
Liquidated and Ascertained Damages & Liquidated Damages \\
Certificate of completion of making good defects & Certificate of making good \\
\hline
\end{tabular}


The parties have to comply with statutory requirements including those in relation to VAT and the Construction Industry Scheme in any event so detailed provisions dealing with these have been removed. The clause requiring insurance to cover employers for loss of liquidated and ascertained damages has been left out of the 2005 suite as have the provisions for nominated subcontractors or suppliers on the grounds that they were not commonly used.

\section{IMPROVEMENTS}

This paper has already touched on some of the improvements in the 2005 JCT suite namely a new consistency in terms of layout and appearance, simplified language and the removal of obsolete clauses. In addition to these largely 'housekeeping' changes, the 2005 suite also include a number of new provisions:

1. Those contracts which include an element of contractor design include an obligation for the contractor to maintain professional indemnity insurance at a level to be agreed between the contracting parties, for a period of either 6 or 12 years (depending on whether the contract is executed under hand or as a deed) and subject to any agreed exclusions or carve outs for pollution, contamination, etc.

2. Again, if the contractor is undertaking any element of design the contracts include a copyright licence as standard. Subject to all monies being paid the employer has an irrevocable licence to use and reproduce the documents prepared by the contractor for any purpose in relation to the works.

3. The design submission procedure developed for the Major Projects Form has been adapted and adopted. If design work or design development is undertaken by the contractor following appointment, schedule 1 contains a design submission procedure which provides the employer with an element of control over how that design is developed.

4. Obligations to provide warranties are included in the Standard Forms of Contract, Design \& Build Contract and Intermediate Building Contract. In addition, the Standard Building Contracts and Design \& Build Contract include the option to confer benefits on third parties pursuant to the Contracts (Rights of Third Parties) Act 1999 instead of calling for warranties.

In addition:

1. Both the Intermediate and Minor Works Building Contracts have been published with a design option in acknowledgement that even simple works may require contractor design.

2. There are new forms of subcontract and sub-subcontract that will help contractors and subcontractors ensure the supply chain is signed up on a similar basis to themselves.

3. There is (or will be) a guide for each form of contract as well as a revised guidance booklet entitled 'Deciding on the appropriate JCT contract'. Available at http://www.jctcontracts.com/JCT/pdf/DecidingontheappropriateJCTcontractFebruary2007-pdf, this document provides a useful introduction to procurement methods, matters that might influence the choice of procurement and a summary of each form of contract and a flowchart to assist users to make a choice about form of contract to use. 
All of the above are welcome additions - by including them the JCT has acknowledged and incorporated revisions which were generally made as standard to the 1998 suite of JCT contracts and has made the entire suite more accessible to users.

\section{SOME OF THE CHANGES IN MORE DETAIL}

\section{Contractor's ability to claim loss and expense and additional time to finish the works}

The list of matters entitling a contractor to claim loss and expense has been substantially shortened from the list included in the 1998 Standard Form of Building Contract with approximate quantities to just seven in the 2005 Standard Building Contract with approximate quantities. While initially this may seem to be to the employer's benefit and the contractor's disadvantage, a more detailed consideration of the relevant clause shows otherwise. The 2005 Standard Building Contract with Approximate Quantities includes at Clause 4.24.5:

\footnotetext{
'an impediment, prevention or default, whether by act or omission, by the Employer, the Architect/ Contract Administrator, the Quantity Surveyor or any of the Employer's Persons except to the extent caused or contributed to by any default, whether by act or omission, of the Contractor or any of the Contractor's Persons'.
}

The grounds which no longer appear in the published form and are seemingly deleted (eg execution of work not forming part of the Contract and supply of materials and goods by the employer) would in fact be allowed as a ground for a claim for an extension of time under the wording set out above so long as it was not contributed to by the contractor's default, etc. A useful example of how simplified drafting can achieve the same result.

The grounds for claiming an extension of time have similarly been reduced in the 2005 suite of contracts. In the case of the with approximate quantities form they have been cut down from 18 to 13 . However, while the list may be shorter the inclusion of 'force majeure' in that list may actually allow the contractor to claim for extra time to complete the works as before.

The way in which claims for extra time to complete the works are calculated has changed significantly and procedures for the contract administrator (or employer under the JCT Design \& Build contract) have tightened up. The global approach has been replaced with a requirement for the contract administrator/architect to attribute extensions of time to specific relevant events instead of confirming which relevant events had been taken into account when making a decision.

\section{Collateral warranties}

All the main contracts include provisions for collateral warranties (except the Major Projects form) and if a subcontract includes design provisions the subcontractor is also required to provide warranties. This is a significant improvement over the 1998 forms of contract, which were silent on the issue of warranties which lead to bespoke drafting if warranties were needed.

The contracts have the flexibility to allow either bespoke forms of warranty to be used or the newly published 2005 set of JCT warranties. The main contractor warranties are to be provided within 14 days of the employer's request while warranties from subcontractors are to be provided within 21 days notices (to allow the contractor time to 
pass the request and warranties through to the subcontractor and back again to the employer).

\section{Third-party rights}

As per warranties, the main contracts include provisions for third-party rights from the contractor instead of warranties if the parties wish to use the Contracts (Rights of Third Parties) Act 1999. This is an innovative and farsighted development which is to be welcomed and it is hoped this will encourage the industry to adopt this approach in preference to the warranty route in future. If third-party rights are to apply, a schedule of rights (which are based on the JCT warranties) are conferred on the third party in question. The schedule of rights is included at the back of the published contract and specific details about the form and type of limitations on liability which are to apply should be completed in the Contract Particulars.

\section{Payment}

While the valuation process in the various form remains unchanged, the payment process has been simplified. The provisions regarding compliance with the Construction Act have been clarified so that the payment notice can more easily be a withholding notice or vice versa as long as the requisite information is included which cuts down on the paperwork required.

If an advance payment is agreed, the assumption is that a bond will be required unless stated otherwise. This is an improvement on the 1998 forms under which a bond was an optional requirement so if the contract was not completed correctly or the entry was overlooked the employer was potentially exposed by paying money upfront without the benefit of any security.

\section{Disputes and dispute resolution}

The 2005 editions acknowledge the availability of alternative forms of dispute resolution and expressly refer to mediation as a means of reaching settlement. Adjudication is still a requirement (in order to comply with the Construction Act) but rather than including bespoke adjudication provisions the 2005 editions rely on the statutory scheme for adjudication with minor revisions. There is still a choice between litigation and arbitration as a way of finally resolving disputes but the default position is litigation unless the Contract Particulars say otherwise.

\section{Termination and insolvency}

While the contracts may still be terminated on the grounds of the other party's insolvency, notice is now required. Previously in most circumstances a JCT contract tended to terminate automatically on insolvency. The definition of insolvency has also been adjusted so that things which may not amount to insolvency under the 1998 forms may do so under the 2005 forms which parties need to be aware of.

\section{A MISSED OPPORTUNITY}

While the updating has gone some way to resolving issues with the previous editions of JCT contract in some respects, it does not go far enough. What is missing/been overlooked?

1. While there are restrictions on use of the contract documents and any design documents developed using the design submission procedure, none of the contracts include confidentiality provisions restricting dissemination of the pricing and design 
information and/or information about the way in which the employer structures transactions and what security is on offer (from either the employer or contractor). This still needs to be built in.

2. There are still no contractual requirements covering provision of programme information by the contractor and/or revised programmes if and when delays occur and/or part or parts of the works are re-sequenced. The only definite dates the employer has are the date of possession and the completion date (which may be extended if extra time is granted to the contractor) so the employer has no way of knowing the way in which the works are being sequenced and neither party necessarily has information to assist in calculating claims for more time.

3. Save for the Major Projects form of contract there is still no definition of practical completion in any of the JCT suite. In Mariner International Hotels Limited v Atlas $L t d^{1}$ the Final Court of Appeal in Hong Kong reviewed English authorities and concluded that practical completion 'is a legal term of art well understood to mean a state of affairs in which the works have been completed free from patent defects other than ones to be ignored as trifling'. However, case law does not acknowledge the raft of documentation which is often required as part of the practical completion process - for example as built information, product guarantees, testing and commissioning certificates - or clients-specific requirements so these will still need to be built in.

4. Looking at the JCT Design \& Build Contract in particular. The contract takes the decision in Co-operative Insurance Society Limited $v$ Henry Boot (Scotland) Ltd ${ }^{2}$ into account and builds on it to clarify that the contractor is only responsible for the design in the Contractor's Proposals. However, this goes against the industry trend of requiring the contractor to take on full design responsibility for all design and to take over the appointments of many or all of the employer's designers. Again, this is something which will often require amendment.

\section{WHAT'S NEW SINCE SPRING 2007}

The JCT and Sweet \& Maxwell continue to add to the updated suite of contracts. For example, the Repair and Maintenance Contract - commercial (which replaces the contracts for use with Works of a Jobbing Character) has been updated as have the contracts for use by homeowners. The process is ongoing though with contracts such as the JCT Construction Management (still awaited) Contract and the JCT Management Building Contract now published as on 10th March, 2008 (together with the associated documentation).

Following changes in both tax and health and safety legislation (Construction Industry Scheme and Construction (Design and Management) Regulations, respectively), amendments to the 2005 and 2006 contracts already available have been published. In addition, the insurance provisions on the Minor Works Contracts have been overhauled to bring them into line with the insurance provisions in the main contracts (namely all risks rather just specified perils) and some housekeeping changes have been made to the warranty and assignment provisions in a number of the published forms. Amendment sheets setting out the various changes are available on http://www.jctcontracts.com. In addition, new editions of the various contracts have been published which incorporate the agreed changes - these are distinguishable from the initial 2005 or 2006 editions by the inclusion of 'revision 12007 ' on the front cover. 
JCT have also launched two brand new contracts in their suite in 2007, the first being the JCT Constructing Excellence Contract (CE). This new contract, which aims to promote collaborative and integrated working, was developed by JCT in conjunction with Constructing Excellence.

Following market feedback on both the binding and nonbinding forms of framework agreement published in 2005, JCT has reviewed the way in which they are drafted. The main issue is that unless amended neither version satisfies EU public procurement rules and there have been calls for the frameworks to provide a guarantee of work. In light of this JCT has now published The Framework Agreement (FA2007).

\section{CONCLUSIONS}

The new suite of contracts is generally welcomed and is a refreshing move with the times. While risk allocation is largely as before the contracts are in a better presentational format achieving a higher level of uniformity and consistency across the suite. The JCT has also taken the opportunity to refresh its suite of building contracts and to add to the family of contracts through the publication of the Constructing Excellence Contract and the Framework Agreement.

The JCT has succeeded in rationalising a complex suite of contract documents for use throughout the various sectors of the industry. With the current economic climate and the imperative of integration and early supply chain involvement post Egan and looking to the likes of the 2012 Construction Commitments and beyond it will be interesting to see whether the JCT model will remain sufficiently able to meet those challenges going forward.

\section{Notes}

1 [2007] HK CFA.

2 TCC 1st July, 2002. 